\title{
A multi-level model of global decision-making: Developing a composite global frame-of-reference
}

\author{
Michael Harvey ${ }^{\mathrm{a}, \mathrm{b}, *}$, David Griffith ${ }^{\mathrm{c}, 1}$, Tim Kiessling $^{\mathrm{d}}$, Miriam Moeller ${ }^{\mathrm{e}}$ \\ ${ }^{a}$ Department of Management, University of Mississippi, United States \\ ${ }^{\mathrm{b}}$ Faculty of Business, Technology, and Sustainable Development, Bond University, Australia \\ ${ }^{\mathrm{c}}$ Department of Marketing, Michigan State University, United States \\ ${ }^{\mathrm{d}}$ Bilkent University, Turkey \\ ${ }^{\mathrm{e}}$ University of Queensland, Australia
}

\section{A R T I C L E I N F O}

\section{Article history:}

Available online 13 January 2011

\section{Keywords:}

Globalization

Global decision-making

Reference Point Theory

Multiple decision points

Externalities

\begin{abstract}
A B S T R A C T
As organizations globalize their operations, managers are finding that making decisions in a global context is more complex. This research develops a multi-level model that examines the influence of group, organizational and society points of reference on managerial decision-making. Reference Point Theory (RPT) is employed as a foundation for a multi-level global decision-making process. The basic premise of RPT is that global managers need to match global environmental conditions with certain reference points. Yet the more dynamic the environment, the greater the risk associated with misinterpreting the appropriate reference points for making global decisions.
\end{abstract}

(c) 2010 Elsevier Inc. All rights reserved.

\section{Introduction}

The globalization of markets has occurred at a faster pace than experts such as Ilinitch, Lewin, and D'Aveni (1998), Harvey and Novicevic (2002) anticipated. This unanticipated change has fundamentally altered the effectiveness of managers' decisionmaking and decision processes employed since the industrial revolution (Farazmand, 2004; Sterman, 1989). The changes occurring in the global business landscape have resulted in a "winner's curse" where managers who were successful in the past are finding it increasingly difficult to repeat their success. We contend that the changes to the global business landscape necessitate a fundamental adjustment to our understanding of managerial decision-making.

The issue of understanding managerial decision-making has been a central focus of business research for decades (Gilovich, Griffin, \& Kahneman, 2002; Jensen \& Kolb, 2000; Kahneman, 2003; Kolb, 1978; Singh, Vitell, Al-Khatib, \& Clark, 2007). Researchers have gained insights into managerial cognitions from an individual perspective, adding insight to the internal factors, such as bounded rationality used by decision makers (cf., Aharoni \& Tihanyi, 2009;

\footnotetext{
* Corresponding author at: University of Mississippi, United States. Tel.: +1 662915 5830; fax: +1662915 7968 .

E-mail addresses: mharvey@bus.olemiss.edu (M. Harvey), griffith@bus.msu.edu (D. Griffith), tkiessli@bond.edu.au (T. Kiessling), mmoeller@bus.olemiss.edu (M. Moeller).

${ }^{1}$ Tel.: +1 517432 6429; fax: +1 5174321112 .
}

Gilovich et al., 2002; Kahneman, 2003), which influences the framing of managerial decisions. The concept of bounded rationality (e.g., global decision makers are imperfect information processors who strive to follow rational models but depart from rational decision-making process to avoid cognitive overload and/ or the lack of complete information) addresses the need to organize information to allow decision makers to make knowledgeable decisions given the complexity of organizational as well as external environments (Aharoni \& Tihanyi, 2009; Ethiraj \& Levinthal, 2004). The dynamic pace of change in today's global marketplace has created even greater challenges for global decision makers that necessitate the modification of rational decision-making models; that heretofore have not been explored extensively in the literature.

Bounded rationality addresses the limitations of global decision makers' ability to address the complexity of making decisions in a global context and their tendency to make satisficing decisions (March \& Simon, 1958; Simon, 1962). Specifically, higher-level factors, such as group, organizational, and society reference points, can have a significantly greater influence on managerial decisionmaking in the globalized business environment today than in the past. It is through the incorporation of a set of reference points (e.g., derived from the group, organizational, and societal levels) in conjunction with the individual global managerial decisionmaking points of reference, that a more holistic understanding of the global decision-making process can be gained. In addition, it is argued that the decision maker must recognize the various relevant reference points when making complex global decisions. 
The purpose of this research is to provide a theoretical foundation for understanding effective decision-making in the new era of globalization. Reference Point Theory (RPT) supports a bounded rationality decision-making framework for global managers. Using RPT as the conceptual anchor for global decisionmaking, we examine how individual managers' can make more efficient global decisions through the use of group(s), the organization, and societal points-of-reference. The model provides a theoretical advance in capturing managerial cognitions based upon the decision makers' bounded rationality supported by RPT.

\subsection{The application of Reference Point Theory to global decision- making}

Reference Point Theory (RPT) can be useful perspective when examining bounded rationality of managers' global decisionmaking (Fiegenbaum, Hart, \& Schendel, 1996). This framing issue is of particular value when making decisions for the first time or when there is inadequate decision-making history to make informed decisions. The basic premise of RPT is that global managers need to match the global environment with appropriate reference points to aid decision-making. The more dynamic the environment, the greater the risk associated with misinterpreting the appropriate reference points for making global decisions (Hopfensitz \& Winden, 2008; Lages \& Lages, 2004).

There are three reference points that managers can use to develop a sense of an appropriate decision to be made in a particular environmental setting, those being: (1) environments that have a past orientation to time (Cohen, Etner, \& Jeleva, 2008). In this situation, the manager uses past decisions as decision guideposts for making future decisions; (2) environments that have a present orientation to decision-making. These environments do not refer to past or future timeframes but rather managers base their decisions on the present environmental conditions; and (3) environments that have a future time perspective for decision-making (see Table 1 ). Managers recognize the changes in environmental context and provide a lens to ascertain relevant and/or irrelevant reference point perspectives for making global decisions in the future. Relative frames-ofreference may be explicit or implicit, but both will influence one's ability/willingness to adjust their global decision-making perspective from one macro-environment to another.

RPT is an attempt to determine the strategic reference points of a global manager as well as certain 'others' that influence the reference point of the manager (Fiegenbaum et al., 1996). The dynamic reference points used by the global manager provide assistance in establishing the risk/return ratio for each decision in a global context. This hierarchical assembling of information aids the global decision maker's attempt to utilize a bounded rationality approach to global decision-making. The assessment of the conduciveness to adjust one's conceptual decision-making framework when entering other environments may be based on past, present and future experiences of the global manager.
Two primary reference indices for constructing a risk assessment for adopting bounded rationality decision-making occurs on an ongoing basis as an organization are internal (i.e., group, individual managers) as well as external (i.e., differences in the macroenvironments). These may be perceived as the various potential referent points which may change over a time continuum of past, present and future. Therefore, global decision-makers may use this reference point perspective to assess the various points-of-view related to strategic decisions at different points in time relative to each macro-environment (Cohen et al., 2008; Hopfensitz \& Winden, 2008). Policies may be directed at modifying the global decisionmaking process as global managers move from one environment (i.e., both macro and organizational) to another over time.

There are potentially three models of risk-taking decision behavior of global managers relative to addressing the adaptation of global decisions. First, global decision-makers may be assumed to be risk adverse relative to making any decisions that pertain to strategic decisions. The global manager's propensity to address the issues associated with making the adjustment in the organization's strategic choices is reduced if the return/reward is insufficient to stimulate a willingness to undertake such risks. Other global managers may make decisions that maximize utility and, therefore, have a positive slope to the risk-taking curve (Schoemaker, 1982). Therefore, a segment of key global managers, at the same time, may be risk takers (i.e., the rewards outweigh the cost/consequences).

It has been hypothesized that global decision-makers are able to increase returns and reduce risk simultaneously by selecting an appropriate reference point for their strategic decision. In addition, to make long-run organizational decisions in an information vacuum, or not tied to some decision context (as explicit or implicit reference points), would be unrealistic and lead to suboptimal global decision-making. When global managers make decisions that are new in an unfamiliar decision context (e.g., global) they need to develop a new set of reference points upon which to base their strategic decisions (Miller \& Ireland, 2005).

There is a third stream of RPT research which speculates that global decision-makers make decisions that are clearly above a reference point and at the same time make other decisions that are below the same reference point. The conclusion that can be drawn from this conceptualization of decision-making is that global managers are both risk-averse and risk-taking, depending on whether the decision-makers perceives themselves to be in a domain of gains or losses relative to changing their reference point to make complex global decisions (Fiegenbaum et al., 1996). It has been argued that the top management team level, global decisionmakers become internal reference points in a specific organizational context for issues such as visualizing the concept of global time (Kahneman \& Tversky, 1979). The question becomes how and which reference point managers will use when they make decisions relative to global strategic choices. This is not to assume that these global managers' decisions are random, but rather, temporally influenced by changes in the internal organizational environment, the increased knowledge of other global organiza-

Table 1

Reference point typology for global decision-making.

\begin{tabular}{|c|c|c|c|}
\hline \multicolumn{4}{|c|}{ Reference point time perspective } \\
\hline Reference points & Past $^{\text {b }}$ & Present & Future \\
\hline Individual & Personal decision-making history & Day-to-day decision-making on current issues & Referent organizations and/or managers \\
\hline Group $^{a}$ & Past membership groups and learning & Present group affiliations and learning & Aspirant groups their membership \\
\hline Organizational & $\begin{array}{l}\text { Organizations that where membership } \\
\text { was held }\end{array}$ & $\begin{array}{l}\text { Membership affiliation and present } \\
\text { frame-of-reference }\end{array}$ & Benchmark organizations or industry standards \\
\hline Societal & $\begin{array}{l}\text { Oriented to past and/or ancestral } \\
\text { pont-of-reference }\end{array}$ & Home country cultural membership & Host countries impact on future decisions \\
\hline
\end{tabular}

\footnotetext{
a Group refers to groups intra-firm groups found in the parent organization and does not address external strategic group membership of the organization.
}

b Past, present and future orientation designations illustrate that any of the four levels may have any one of the three time orientations. 
tions tolerance of a particular concept of time (i.e., past, present, or future) at a point-in-time as well as, the exact points of reference they use in their decisions.

The concept of reference points for global decision-making is based upon the psychological precept that individuals' perception mechanisms are thought to better calculate differences, rather than absolute levels when evaluating alternatives (Festinger, 1954). In addition, decision-makers attempt to make decisions that satisfics the decision rather than to attempt to maximize global decisions. Although there are others who are concerned that there is no formal theory for determining reference points for decisionmakers (Tversky \& Kahneman, 1986). It is assumed the RPT can make a contribution in determining the risk-taking posture of global managers when addressing the complex, multifaceted issues associated with developing grand global strategies.

Examining the risk perspective of various global managers/ stakeholders is critical but at the same time the return or "benefit" derived from reducing the level of uncertainty in the global organization is also important. The perceived payback from acting on reference point information/input relative to implementing a global plan is synchronization of global managers to a consistent understanding of the origins of their reference points. The benefits derived from reducing the conduciveness of the environment to multiple perceptions may also have long-run benefits (e.g., increased adaptation to local standards, less conflict between the employees and management, higher-level of coordination of events to local social customs). Therefore, it would seem only logical that global managers as a whole will have to take a stance on global strategic plans to establish an environment that is known for being in step with local environments (e.g., thinking globally while acting locally) (Brock \& Siscovick, 2007).

RPT assists global managers in calibrating their decisionmaking process relative to the risks associated with global strategic decisions. The rate of change taking place and the lack of relevant decision-making experience (i.e., an adequate and/or an appropriate decision frame-of-reference) in the global marketplace necessitates that global managers test and retest their reference points relative to the strategic decision-making process. This enables the global manager to maintain a set of dynamic points of reference. To gain additional insight into how RPT may be used as a means to structure global managers' decision-making, a multilevel model of global decision-making is presented that illustrates the individual, group, organizational and societal levels as references for individual global managers. The following section of the paper illustrates such a multi-level model of global decisionmaking.

\section{The multi-level model of global decision-making: individual, group, organizational and societal levels}

There are four levels (i.e., individual, group, organizational, and societal) that can provide valuable reference points for an individual manager's global decision-making. For a greater understanding of effective decision-making in the global context when employing RPT, it is necessary to understand the influence of the higher-level elements on the individual level. As such, the unique higher-levels need to be combined into a multi-level model of global decision-making (i.e., 'grand' global decision-making strategy). However, prior to delving into the higher order effects, it is important to understand the complexity of individual level global decision-making.

\subsection{Individual level of global decision-making}

Harvey and Novicevic (2002) argue that there are four elements in the individual decision-making level that need to be assessed to determine the decision-making capabilities of global managers, they are: (1) multiple IQs of global managers (e.g., political, network, social, emotional, cultural, innovative, intuitive, and organizational); (2) learning styles of potential global managers (e.g., accommodator, assimilator, diverger, or converger); (3) thinking styles of global managers (e.g., monarchic, hierarchic, oligarchic or anarchic); and (4) type(s) of tasks to be undertaken in particularly environmental (i.e., internal and external) settings during overseas assignment for the global manager.

First, the decision-making skills of global managers can initially start by using a set of multiple IQs as indicators of the potential diverse abilities of global decision makers. For example, global manager IQs can be grouped into three individual categories of analytical intelligence, creative intelligence, and practical intelligence as suggested by the triarchic theory of human intelligence (Sternberg, 1985, 1996) as well as a fourth called organizational intelligence (Davenport \& Prusak, 1998; Sternberg \& Smith, 1985; Wagner \& Sternberg, 1986). Analytical intelligence is the planning, implementation, and evaluation of problem-solving processes and knowledge acquisition. Creative intelligence is the individual ability to develop innovative solutions to new problems encountered in novel environments. Practical intelligence is the individual tacit knowledge that draws on common sense, intuition, and 'street-smarts' knowledge to adapt to an environment or to shape the environment to the problem at hand. Organizational IQ is that the global manager has a detailed and accurate understanding/ insight as to how the organization operates both functionally and the time that is needed to accomplish goals. The employment of multiple categories of managerial IQs presents a more holistic perspective on the potential diverse abilities of global decision makers.

Second, researchers have identified a number of distinct learning styles that are used by individuals when they are attempting to understand new information. These learning styles appear to be universal with slight variations but remaining in one of four categories (Jensen \& Kolb, 2000; Kolb, 1978). Kolb (1974, 1985) and Vincent and Ross (2001) have identified the learning styles of divergent, convergent, assimilating, and accommodative. Given that global managers can have different learning styles, it is important to take these differences into consideration when developing training materials and/or development sessions. It is also important to monitor learning styles for managers from different cultures in that there will be slight differences in preferences for how to learn within each learning category.

Third, thinking styles involve integrative utilization of global managers' cognitive abilities and learning styles that affect their decision-making. Individual thinking styles have been explored and vary from single-minded driven individuals (monarchical thinking style), leaders who establish agendas and priorities (hierarchical thinking style), those that multitask and take on multiple assignments (oligarchial thinking style) and appear to be disorganized and random in their thinking, but offer highly creative solutions (anarchical thinking style) (Sternberg, 1997). Fundamental differences in the style of thinking of global managers create the need for not only adaptations of information for training, but also for the manner in which information is presented on a day-by-day basis. For, if the information presented to a manager does not fit with his/her thinking style, effectiveness is lost.

Fourth, the nature of the assignment and the type of task/skill requirements can have a significant impact on the decisionmaking of global managers. A manager must first determine the type of the assigned tasks that make-up his/her overseas assignment. Tasks related to overseas assignments can be coordinative (i.e., tasks that require global managers to facilitate activities between two or more entities within or outside requiring 
a higher-level of cultural adjustment/awareness), computational (i.e., tasks that require global managers to interface with systems/ computers in the organization, thereby requiring less interpersonal cross-cultural competencies), creative (i.e., tasks requiring a level of curiosity and creativity) and combination (i.e., tasks that require the manager to do more than one type of core task requiring additional managerial skills). Most important to consider pertaining to task/skill requirements is whether these occur within the internal or external environment.

Important internal organizational environment factors that increase the difficulty for the global manager include the problems associated with managing in foreign hybrid organizational environments which can be represented by combined ownership (i.e., joint ventures, strategic alliances), the top-managements' attitude relative to the strategic importance of the host country operations/market, and the history of the organization's prior experience in the host country market. This information is organization-specific and could have an impact on the global managers' ability to accomplish the task through the development of cross-cultural competencies relative to specific objectives during the foreign assignment (Debebe, 2008). The most salient external environment factor to consider is the cultural distance between the country of the global manager's assignment and the home country of that manager (while a great deal of controversy relates to the concept of cultural distance (e.g., Shenkar, 2001; Tihanyi, Griffith, \& Russell, 2005) its general concept is useful for conceptualizing cross-national space (Sousa \& Bradley, 2006; Tihanyi et al., 2005), political risk and economic instability of the host country).

\subsection{Group level of global decision-making}

Once the individual level of global decision-making has been assessed, the next level in the multi-level model of global decisionmaking that needs to be assessed is that of the group. Groups are conceptualized as sub-organizational affiliations (e.g., sub-sets of members of organizations, but groups can also extend beyond the firm's boundaries when the group incorporates members of the firm's buyers or suppliers) and play a significant role in a global organization and add a level of complexity to global decisionmaking (Keys \& Schwartz, 2007; Miller \& Ireland, 2005). These operational groups can provide a foundational reference point for acceptable decision-making by the global manager. Group level elements that should be assessed to determine the decisionmaking capabilities of global managers include the size and level of diversity of the global group, the longevity and/or tenure of the global group as a whole, the level of global group cohesiveness, and the level of global group creativity and the type of leadership in the global group.

The actual size of the group has an impact on the global decision-making properties of the group. Larger groups that are geographically dispersed (e.g., global virtual teams, global account management teams) have a more difficult time making decisions and their decisions generally will take longer to be formulated (Harvey \& Griffith, 2007) than smaller groups. The premise behind the development of global groups, such as global virtual teams, is to enhance the abilities and creativity of people distributed throughout the organization and to culminate individual expertise that spans organizational boundaries determining the efforts of a global groups/teams (Harvey \& Griffith, 2007; Townsend, DeMarie, \& Hendrickson, 1998). These somewhat temporary large teams can permit global managers to handle a greater number of projects that may be more contextual and complex than other organizational problems (Nemiro, 2001; Potter, Cooke, \& Balthazard, 2000). However, too much diversity will created confusion and a lack of majority support for ideas/strategies (Gibson, Randel, \& Earley,
2000; Schein, 1996). It is important to note that group diversity is not just observable diversity (e.g., age, gender, ethnicity, nationality and the like) but also 'invisible' diversity (i.e., emotional IQ political IQ; Network IQ, cultural/social IQ and the like) found in the group (Harvey, Novicevic, \& Garrison, 2005). By assessing both sets of diversity (i.e., visible/invisible), the decision-making capabilities of the group can be better understood and the expected level of quality of global decision-making estimated.

The length of time that a group has existed can be used to estimate the ability to effectively accomplish global decisionmaking and to a lesser degree, the quality of decisions made by the group entity. Groups that have 'tenure' or that represent an official part of the organization (e.g., marketing, accounting, finance departments), are more likely to have official standard operating procedures that can be used in making routine decisions, if there are such types of global decisions (Pelled, 1996; Pelled \& Eisenhardt, 1999) than groups with less tenure. While the relationship between tenure and attaining goals is curvilinear, the need for stature in the organization is a critical element in developing legitimate authority in a global organization (Griffith \& Ryans, 1997). Groups that have an organizational history should have well developed procedures/processes to accomplish tasks in the organization due to their historic position of authority and/or power. Groups that do not have influence, seldom remain viable in complex organizations.

Team cohesiveness can be measured by group social capital. Social capital is defined as an asset that is engendered via social relations that can be employed to facilitate action and achieve above-normal rents (Adler \& Kwon, 2002; Baker, 1990; Griffith \& Harvey, 2004; Leana \& Van Buren, 1999). In a global management context, social capital has been primarily conceptualized as a resource reflecting the character of social relations within a firm (Kostova \& Roth, 2003) that extends beyond group boundaries providing a basis for action. Two productive underlying dimensions are common to existing conceptualizations of social capital and are germane to global group decision-making: associability and trust (Griffith \& Harvey, 2004; Leana \& Van Buren, 1999). Associability is defined as the willingness and ability of group members to subordinate individual level goals and associated actions to collective goals and actions (Leana \& Van Buren, 1999). The inherent subornation of individual goals through participation in the collective however is not a relinquishment of individual goals, but rather a restraining mechanism to accomplish group goals. Trust is defined as when one has confidence in another group member's actions and intentions (Das \& Teng, 1998; Leana \& Van Buren, 1999). It has been asserted that co-operative, long-term group relationships are dependent upon the fostering of trust (Das \& Teng, 1998). Researchers have proposed that trust can be considered in terms of a risk-reward relationship (Williamson, 1993), where predictable actions by one global group member allows the relationship to operate more effectively. The dimensions of associability and trust are both attributes of the group as well as the individual (Griffith \& Harvey, 2004). Therefore, social capital can be conceptualized as an attribute of a collective, as well as the sum of the individual relations.

Group creativity is thought to be the creation of a valuable/ useful, idea, procedure, or process by individuals in the group working together in a complex social system (Woodman, Sawyer, \& Griffin, 1993). While there are a number of different opinions on what will stimulate creativity in a group, there are some commonly held views of what promotes creativity in groups. Group creativity is influenced by the composition of the group (e.g., creativity characteristics/levels and group), the type of leadership that the group has, the availability of resources needed to undertake creative processes (e.g., information, technology to process information, time and the like), the communication infrastructure 
and group processes to facility communications and decisionmaking, the individual group member characteristics like intellectual abilities, thinking styles, motivation, personality and the like, and the environmental context of the group (Drazin, Glynn, \& Kazanjian, 1993; Goncalo \& Staw, 2006; Paulus, Larey, \& Dzindolet, 2000; Paulus \& Yang, 2000; West, 2002).

It is important to understand that global managers actively participate in groups and therefore that their individual decisionmaking is effected by the group level elements to which they are exposed. Given that each of these group level factors has advantages and disadvantages for effective decision-making, it becomes important for the individual manager to draw from these group elements specific reference points that can provide for optimal individual decision-making. Furthermore, the participation in groups creates multiple reference points from which a manager can draw to more effectively and efficiently make his/her decisions.

\subsection{Organizational level of global decision-making}

Once the influence of the group level on individual decisionmaking has been assessed, the next level in the multi-level model of global decision-making that needs to be addressed is that of the organization. There are similarities between group and organizational global decision-making and distinctive influences on resultant individual decision-making. For example, the degree of decision-making autonomy in the organizational unit making the global decision, the organizational context (e.g., type of ownership, control, and accountability), the stage of evolution of the organization's strategic 'outlook' (i.e., international, multination, global) as well as ethnocentric, regiocentric, polycentric, geocentric and the time orientation of decision-makers in the global organizational unit, all influence the organization's decisionmaking as well as the individual global managers operating within the organization.

For example, the decision-making opportunities of operating entities in the global organization network are predicated on the level of autonomy that is given to decision makers in overseas subsidiaries. The degree to which a parent-subsidiary relationship requires interdependence influences the level of decision-making autonomy, control (Baliga \& Jaeger, 1984; Dong, Zou, \& Taylor, 2008), monitoring (Nilakant \& Rao, 1994), and ultimately the type of governance structure (e.g., a subsidiary manager's ability to make independent decisions) when strategic decisions are implemented (Hannon, Huang, \& Jaw, 1995). When low levels of interdependence are required for global decision-making between the parent and subsidiary or among subsidiaries, the subsidiary typically has a great deal of strategic autonomy regarding its global decision-making (Dong et al., 2008; Nohria \& Ghoshal, 1994; Roth \& O’Donnell, 1996; Wright \& McMahan, 1992). Alternatively, when the parent-subsidiary relationship involves higher-levels of interdependence (i.e., higher coordination demands), headquarters' must rely on more complex governance arrangements and frequently will implement a combination of both behavior/ controls, output (e.g., compensation), and social controls where social controls (i.e., trust and commitment) become important in managing the relationship (Eisenhardt, 1985; Martinez \& Jarillo, 1989; Ouchi, 1979; Roth \& Nigh, 1992; Taylor \& Okazaki, 2006). The integration of social control into parent-subsidiary relationships has been advocated (Nohria \& Ghoshal, 1994; Roth \& Nigh, 1992; Roth \& O'Donnell, 1996) and is seen as an integrative tool to bridge the complexity inherent in global decision-making.

The strategic orientation of managers/organizations also influence decision-making. One of the most frequently used strategic orientation models is that of domestic, international, multinational, and global (cf., Bartlett \& Ghoshal, 1987). Under each approach the strategic focus and decision-making rules differ to take into account the decision-making orientation of the managers. As such, the specific approach the firm operates under (e.g., domestic or global) sets the foundational reference point of that organization (or global network) influencing decision-making that works to coordinate decisions throughout the world.

Another strategic orientation influential in decision-making has been ethnocentric (e.g., home country orientation \{domestic strategy\}), polycentric (e.g., host country orientation \{international strategy\}), regiocentric (e.g., regional trading block strategy \{multinational strategy\}, and geocentric (e.g., truly global orientation \{global strategy\}) (Heenan \& Perlmutter, 1979; Perlmutter, 1969). These issues permeate more than staffing, but also influence elements of the firm's market assessment, product development, marketing strategy, etc. The focus of strategic decision-making is captured in the scope of operation, or frame-of-reference, of managers (Bartlett \& Ghoshal, 1989; Scullion \& Collings, 2006). The specific orientation selected indirectly influences the decisions of global managers.

Furthermore, it is imperative to recognize that the meaning of time varies across societies, organizations (and other groups) as well as among individuals (Harvey \& Griffith, 2007; Hofstede, 1991; McGrath \& Kelly, 1986; Trompenaars, 1997). Time can have a direct impact on global decision-making and a global managers' ability to effectively accomplish strategic tasks (Harvey \& Griffith, 2007). Consequently, the complexity and ambiguity that surround the temporal aspects of global business significantly complicate the role that global managers play in the decision-making process of their foreign operations (Harvey \& Novicevic, 2001). The embedding of time into the basic fabric of decision-making compels global managers to address the variation between the home country and host country differences in the basic dimensions of time (Ganitsky \& Watzke, 1990).

Thus, from a multi-level model perspective, managers operate within groups, which are embedded within organizations. The organizational policies, strategies and approaches, influence the groups directly and the individual managers indirectly. Given that each of these organizational level factors shape the decisionmaking parameters, it becomes important for the individual manager to draw from these organizational elements specific reference points that can provide for optimal individual decisionmaking. Further, the participation in groups creates multiple reference points from which the manager can draw to more effectively and efficiently make decisions.

\subsection{Societal level of global decision-making}

The highest level of assessment of the multi-level global decision-making model is that of the society in which the global manager's decision-making is taking place. The macro-environment provides the landscape for making decisions and provides a set of reference points for global managers. For example, issues such as the level of economic development in the host country, the level and nature of poverty in the host country, the cultural difference between the host country and that of the home country of the global manager, the level of 'openness' (i.e., transparency in the host country $\{$ e.g., economic, political, and social\}), and the societal assessment of the potential externalities of a global manager's decision-making need to be taken into consideration when global managers make decisions as each of these factors sets forth a parameter on decision-making.

Rostow (1959, 1990) developed a model of economic growth that identified five different stages of economic development: the traditional society, the preconditions for take-off, the take-off, drive to maturity, and the age of high mass-consumption. In categorizing economies into different groups, it is possible to 
identify the key considerations in each type of economy and their potential influence on a manager's decision-making. For example, differences in economic growth signal differences in the amount of investment in capital equipment and infrastructure development, which may influence the manager's decisions. While stage models are criticized for taking a very Anglocentric point-of-view, these models can provide a panorama of issues that global managers need to take into consideration when determining the influence of host countries level of economic develop on decisions.

The level and nature of poverty in the host country is another aspect of the societal level of global decision-making to be considered. Economic development is increasingly viewed as a way to eliminate (or decrease) poverty in "Base of the Pyramid" (BoP) of developing countries, where the average daily income is $\$ 2$ or less (Hart, 2005; Prahalad, 2005) but will have 7/8ths of the world's population by the year 2050. While the "average" may be less than \$2/day, wide income disparities exist even within countries - from rural to urban, and within urban settings. Nevertheless, even within the poorer sections of such countries, multinational and local firms are starting to tap these markets (Napier \& Harvey, 2008; Prahalad, 2005), thus providing new reference points for global managers.

Further, the differences in culture among countries of the world are well documented (e.g., Hofstede, 1991; Trompenaars, 1997). Decision-making will be indirectly as well as directly impacted by the nature of the host country's culture in which global managers are making decisions (Brettel, Engelen, Heinemann, \& Vadhanasundhu, 2008; Griffith, Myers, \& Harvey, 2006). The home country culture of the global manager is an imprint on the manager's way of thinking that cannot be avoided regardless of where the decision-making takes place. This influence of culture is most evident when the decision being made will be implemented throughout the global network of an organization (e.g., the decision having differing influence in each culture due to the uniqueness's in each cultures). The cultural distance between countries becomes a critical dimension of decision-making of global managers for both understanding the decisions made within the global organization, but also in compliance with that decision in the local market. Therefore, it is imperative that the global manager has a means to analyze cultures to calibrate the level of differences. Hofstede's cultural analysis (i.e., individualism vs. collectivism, power distance; uncertainty avoidance, masculinity vs. femininity, and time orientation) is typically sited as one of the better means to determine difference between countries, although with limitations (Shenkar, 2001; Tihanyi et al., 2005).

In transitional and post-communist economies, the government controlled the free market. Decision-making was centralized with little autonomy allowed to individuals. Employees developed "ironic freedom" (i.e., the freedom of not identifying themselves with the system) (White, 1979) and thus worked around the system. Developing countries often have onerous tax burdens, duties, tithes, and other destructive controls that compounded the costly effects of living within the system giving only limited credence to western ways of doing business. Specifically, it is suggested that the only way an individual could "get ahead" would be to participate in the black market, or circumvent established controls and the established system. Therefore global manager's brought up in this system will have difficulty in communicating globally due to their set reference points.

Finally, issues related to the unintended consequences of global decision-making by managers can influence reference point determination. For decades, economists have examined the unintended costs and/or benefits of exchange to third parties or individuals who are not directly involved in the exchange transaction or consequences of the exchange outside the price system (Ayres \& Kneese, 1969; Greenwald \& Stiglitz, 1986; Henderson, 1997). Past researchers have made a distinction between parties impacted by these resulting externalities: first order - impact of unintended and/or unanticipated consequences of parties involved in the exchange process; second order - impact of unintended and/or unanticipated consequences of parties not involved in the exchange process; third order - impact on organizations not involved in the exchange process; and fourth order - societal impact from the global decision (Mundt, 1993).

Two examples help to illustrate the difference between first and second order externalities. In the first case, an employee is routinely directly impacted by the organization's decision. The unanticipated/unintentional outcome of the global decision directly impacts one of the two members involved in the decision. The 'injured party' is one who was not a part of the exchange process, that being the non-interacting organization or the general population. In both cases, there are explicit and implicit costs associated with the externalities to the parties involved in the exchange process, plus non-interacting third parties (Mundt, 1993). In an effort to develop strategies to address the externalities due to global decisions made in organizations, the concept of externalities needs to be expanded.

Table 2 illustrates the expansion of global decision-making in an organization (see Table 2). There are two orders (or levels) of influence of those unintentionally impacted. The delineation of global decision-making to non-interacting individuals (i.e., 'others') and the implicit nature of some aspect of global decision-making (i.e., some aspect of the decision that goes against the mores of the culture) helps to illustrate the sub rose impact of an overt destructive act. Under the expanded view of externalities, the first order (i.e., individual-to-individual) impacted by the global decision remains the same. But, in addition, there can be first order externalities between the individual and an organization, since both the individual and organization can be a party to the global decision (i.e., it impacts them directly).

Beyond the direct participants in the exchange process, a variety of secondary effects can be influenced by the organization's global decision and thereby, impact individuals and ultimately the organization as whole who were not a part of the decision. In the present 'green' societal expectations, the issue of global decisionmaking externalities needs to be carefully considered by global managers as these externalities set new reference points which can help to paramaterize decision-making at the individual level.

Table 2

Decision-making externalities and their global impact matrix.

\begin{tabular}{|c|c|c|c|c|c|c|c|c|c|c|}
\hline \multirow{2}{*}{$\begin{array}{l}\text { Initiator/recipient } \\
\text { Externality impact }\end{array}$} & \multicolumn{2}{|c|}{ First order individual } & \multicolumn{2}{|c|}{ Second order group } & \multicolumn{2}{|c|}{$\begin{array}{l}\text { Third Order } \\
\text { Organizational }\end{array}$} & \multicolumn{2}{|c|}{ Fourth Order Societal } & \multicolumn{2}{|c|}{ Composite summation } \\
\hline & Tangible & Intangible & Tangible & Intangible & Tangible & Intangible & Tangible & Intangible & Tangible & Intangible \\
\hline Individual & $\begin{array}{l}\text { Positive } \\
\text { Negative }\end{array}$ & & & & & & & & & \\
\hline Organization & $\begin{array}{l}\text { Positive } \\
\text { Negative }\end{array}$ & & & & & & & & & \\
\hline
\end{tabular}




\section{Conclusion}

Globalization and the speed of change in the marketplace have put a strain on managers' ability to make global decisions. Even more problematic, managers that have been successful in the past may have decision-making logic based upon outdated points-ofreference that no longer apply or are ethnocentric in nature. This research contributes to the theoretical literature on decisionmaking by identifying multiple levels of influence on global manager decision-making based upon the guiding principles of Reference Point Theory. RPT provides a strong theoretical foundation for the study of decision-making since the basic premise of RPT is that global managers need to match the global environmental conditions (e.g., nature of the macro-environment), with reference points of the internal organization culture, affiliated groups in the organization and the individual manager's point-ofreference (which set the foundation of an individual manager's rationality). With the multi-level model outlined, future research can work to specify how manager's select reference points, the magnitude of influence of each level of influence, as well as the individual factors that allow for effective reference point adjustment.

\subsection{Managerial relevance}

The managerial implications of this paper are based on the premise that global managers need to determine a priori what are the relevant reference points for making efficient as well as effective decisions in a global context. Frequently, these reference points may be different from those used to make decisions in a multinational context. Adjusting decision reference points may allow global managers to integrate the insight and wisdom of multiple influencers (e.g., group, organizational and societal) into global managerial decisions. Without this revision of global decision-making, managers will lack the proper perspective (e.g., past, present, and future) to implement global decisions. In addition, global managers will need to develop new decision processes that can be developed based upon input from multiple reference points.

The more dynamic the global environment the greater the risk associated with misinterpreting the appropriate reference points for making global decisions, especially when faced with multiple levels of reference points. In addition, global managers may have to develop a set of dynamic reference points to develop appropriate or satisficing decision heuristics, which are based upon reference points in groups, organizations, and the macro-environment. These reference points become the foundation for making effective global decisions.

In conclusion, this research explored managerial decisionmaking from a theoretical perspective noting the difficulties and risks associated with making global decisions. RPT provides a unique perspective on how to integrate relevant points of view when developing a new decision or decision-making process. As such, this theoretical foundation provides the guidelines for global decision-making. Many issues that need further investigation have arisen from this investigation; from the appropriate selection of these individuals to internally developing a corporate culture to assist in this high speed environment to the ability to more accurately assess group, organizational and societal factors so as to more accurately account for these influences on managerial references points. What appears to be certain relative to global decision-making is that due to the complicated and often risky nature of cumulative individual decision-making behavior (and thus the collection of potentially unintended consequences), global flexibility and creativity will be required.

\section{References}

Adler, P., \& Kwon, S. (2002). Social capital: Prospects for a new concept. Academy of Management Review, 27(1): 17-40.

Aharoni, Y., \& Tihanyi, L. (2009). Managerial decision-making in international business research. Working Paper Series. Texas A\&M University, College Station, TX.

Ayres, R., \& Kneese, A. (1969). Production, consumption and externalities. American Economic Review, 59(3): 282-297.

Baker, W. (1990). Market networks and corporate behavior. American Journal of Sociology, 96: 589-625.

Baliga, B. R., \& Jaeger, A. M. (1984). Multinational corporations: Control systems and delegation issues. Journal of International Business Studies, Fall: 25-40.

Bartlett, C. A., \& Ghoshal, S. (1987). Managing across borders: New strategic requirements. Sloan Management Review, 28: 7-17.

Bartlett, C. A., \& Ghoshal, S. (1989). Managing across borders: The transnational solution. Boston: Harvard Business School Press.

Brettel, M., Engelen, A., Heinemann, F., \& Vadhanasundhu, P. (2008). Antecedents of market orientation: A cross-cultural comparison. Journal of International Marketing, 16(2): 84-119.

Brock, D., \& Siscovick, I. C. (2007). Global integration and local responsiveness in multinational subsidiaries: Some strategy, structure, and human resource contingencies. Asia Pacific Journal of Human Resources, 45(3): 353-373.

Cohen, M., Etner, J., \& Jeleva, M. (2008). Dynamic decision-making when risk perception depends on past experience. Theory and Decision, 64(2-3): 173-192.

Das, T., \& Teng, B. S. (1998). Resource and risk management in the strategic alliance making process. Journal of Management, 24: 21-42.

Davenport, T., \& Prusak, L. (1998). Working knowledge: How organizations manage what they know. Boston, MA: Harvard Business School Press.

Debebe, G. (2008). Cross-cultural competence and power-based rules: A native American case study. International Journal of Intercultural Relations, 32: 399-414.

Dong, B., Zou, S., \& Taylor, C. R. (2008). Factors the influence multinational corporations' control of their operations in foreign markets: An empirical investigation. Journal of International Marketing, 16(1): 98-119.

Drazin, R., Glynn, M., \& Kazanjian, R. (1993). Multilevel theorizing about creativity in organizations: A sensemaking perspective. Academy of Management Review, 24(2): 296-307.

Eisenhardt, K. (1985). Control: Organizational and economic approaches. Management Science, 31(2): 134-149.

Ethiraj, S., \& Levinthal, D. (2004). Bounded rationality and the search for organizational architecture: An evolutionary perspective on the design of organizations and their evolvaility. Administrative Science Quarterly, 49: 404-437.

Farazmand, A. (2004). Building capacity in the age of globalization. Public Organization Review, 4(1): 3-24

Festinger, L. (1954). A theory of social comparison processes. Human Relations, 7(2): $117-140$.

Fiegenbaum, A., Hart, S., \& Schendel, D. (1996). Strategic reference point theory. Strategic Management Journal, 17: 219-235.

Ganitsky, J., \& Watzke, G. (1990). Implications of different time perspectives for human resource management in international joint ventures. Management International Review, Special Issue: 37-51.

Gibson, G. B., Randel, A. P., \& Earley, P. G. (2000). Understanding group efficacy: An empirical test of multiple assessment methods. Group and Organization Management, 25(1): 67-98.

Gilovich, T., Griffin, D., \& Kahneman, D. (2002). The psychology of judgement: Heuristics and biases. New York: Cambridge University Press.

Goncalo, J., \& Staw, B. (2006). Individualism-collectivism and group creativity. Organizational Behavior and Human Decision Processes, 100(1): 96-109.

Greenwald, B., \& Stiglitz, J. (1986). Externalities in economies with imperfect information and incomplete markets. Quarterly Journal of Economics, 101(2): 229-264.

Griffith, D. A., \& Harvey, M. (2004). The influence of individual and firm level social capital of marketing managers in a firm's global network. Journal of World Business, 39(3): 244-254

Griffith, D. A., \& Ryans, J. K., Jr. (1997). Organizing global communications to minimize private spill-over damage to brand equity. Journal of World Business, 32(3): 189202

Griffith, D. A., Myers, M. B., \& Harvey, M. (2006). An investigation of national culture's influence on relationship and knowledge development in Japan and Unites States intra- and inter-cultural inter-organizational exchanges. Journal of International Marketing, 14(3): 1-32.

Hannon, J. M., Huang, I., \& Jaw, B. (1995). International human resource strategy and its determinants: The case of subsidiaries in Taiwan. Journal of International Business Studies, 26(3): 531-554.

Hart, S. (2005). Capitalism at the crossroads. Philadelphia: Wharton Business School Publishing.

Harvey, M., \& Griffith, D. A. (2007). The role of globalization, time acceleration and virtual global teams in fostering successful global product launches. Journal of Product Innovation Management, 24(5): 486-501.

Harvey, M., \& Novicevic, M. (2001). The impact of hypercompetitive 'timescapes' on the development of a global mindset. Management Decision Journal, 39(6): 70-82.

Harvey, M., \& Novicevic, M. (2002). The hypercompetitive global marketplace: The important of intuition and creativity in expatriate managers. Journal of World Business, 27: 127-138.

Harvey, M., Novicevic, M., \& Garrison, G. (2005). Global virtual teams: A human resource capital architecture. International Journal of Human Resource Management, 16(9): 1583-1599. 
Heenan, D., \& Perlmutter, H. (1979). Multinational organizational development. Reading, MA: Addison-Wesley.

Henderson, V. (1997). Externalities and industrial development. Journal of Urban Economics, 42(3): 449-470.

Hofstede, G. (1991). Culture and organizations: Software of the mind. London: McGraw-Hill.

Hopfensitz, A., \& Winden, F. (2008). Dynamic choice, independence and emotions. Theory and Decision, 64(2-3): 249-300.

Ilinitch, A., Lewin, A., \& D'Aveni, R. (1998). Managing in times of disorder: Hypercompetitive organizational responses. Thousand Oaks, CA: Sage Publications.

Jensen, P., \& Kolb, D. A. (2000). Learning style and meaning making in conversation. In R. J. Riding \& S. G. Rayner (Eds.), International perspectives on group differences (pp. 125-148). Stamford, CT: Ablex.

Kahneman, D., \& Tversky, A. (1979). Prospect theory: An analysis of decisions under risk. Econometrics, 47: 262-291.

Kahneman, D. (2003). A perspective on judgment and choice: Mapping bounded rationality. American Psychologist, 58(9): 672-697.

Keys, D., \& Schwartz, B. (2007). Leaky" rationality: How research on behavioral decision-making challenges normative standards of rationality. Perspectives on Psychological Science, 2(2): 162-180.

Kolb, D. A. (1974). On management and the learning process. In D. A. Kolb, I. M. Rubin, \& J. M. McIntyre (Eds.), Organization psychology: An experimental approach (pp. 7485). Englewood Cliffs, NJ: Prentice-Hall, Inc.

Kolb, D. A. (1978). Learning style inventory technical manual. Boston, MA: McBer \& Co.

Kolb, D. A. (1985). Learning style inventory. Boston, MA: McBer and Company.

Kostova, T., \& Roth, T. (2003). Social capital in multinational corporations and a micromacro model of its formation. Academy of Management Review, 28(2): 97-103.

Lages, L. F., \& Lages, C. R. (2004). The STEP scale: A measure of short-term export performance improvement. Journal of International Marketing, 12(1): 36-56.

Leana, C., \& Van Buren, H., III (1999). Organizational social capital and employment practices. Academy of Management Review, 24: 538-555.

March, \& Simon, (1958). Organizations. New York: Wiley.

Martinez, J., \& Jarillo, J. (1989). The evolution of research on coordination mechanisms in multi-cultural corporations. Journal of International Business Studies, 20(3): 489514.

McGrath, J., \& Kelly, J. (1986). Time and human interaction: Toward a social psychology of time. New York: Guilford Press Inc

Miller, C., \& Ireland, D. (2005). Intuition in strategic decision-making: Friend or foe in the fast-paced 21st Century. Engineering Management Review, IEEE, 33(2): 30-40.

Mundt, J. (1993). Externalities: Uncalculated outcomes of exchange. Journal of Macromarketing, 13(2): 46-53.

Napier, N., \& Harvey, M. (2008). Management education at the base of the pyramid: The impossible dream? Journal of Management Education, 36(2): 76-88.

Nemiro, J. E. (2001). Connection in creative virtual teams. Journal of Behavioral and Applied Management, 3(2): 92-112.

Nilakant, V., \& Rao, H. (1994). Agency theory and uncertainty in organizations: An evaluation. Organization Studies, 15: 649-672.

Nohria, N., \& Ghoshal, S. (1994). Differentiated fit and shared values: Alternatives for managing parent-subsidiary relations. Strategic Management Journal, 15: 491-502.

Ouchi, W. (1979). A conceptual framework for the design of organizational control mechanisms. Management Science, 25: 833-848.

Paulus, P., Larey, T., \& Dzindolet, M. (2000). Creativity in groups and teams. In M. Turner (Ed.), Groups at work: Advances in theory and research (pp. 319-338). Hillsdale, NJ: Lawrence Erlbaum.

Paulus, P., \& Yang, H.-C. (2000). Idea generation in groups: A basis for creativity in organizations. Organizational Behavior and Human Decision Processes, 82(1): 76-87.

Pelled, L. (1996). Demographic diversity, conflict, and work group outcomes: An intervening process theory. Organizational Science, 7(6): 614-631.

Pelled, L., \& Eisenhardt, K. (1999). Exploring the black box: An analysis of work group diversity, conflict, and performance. Administrative Science Quarterly, 44: 1-28.

Perlmutter, H. (1969). The tortuous evolution of the multinational corporation. Columbia Journal of World Business, 4: 9-18.

Prahalad, C. K. (2005). The fortune at the bottom of the pyramid. Philadelphia: Wharton Business School Publishing.

Potter, R., Cooke, R., \& Balthazard, P. (2000). Virtual team interaction: Assessment, consequences, and management. Team Performance Management, 6(7/8): 131-137.
Rostow, W. W. (1959). The stages of economic growth. The Economic History Review, 12(1): 1-16.

Rostow, W. W. (1990). Theories of economic growth from David Hume to the present. Oxford, UK: Oxford University.

Roth, K., \& Nigh, D. (1992). The effectiveness of parent-subsidiary relationships: The role of coordination, control, and conflict. Journal of Business Research, 25: 277-301.

Roth, K, \& O'Donnell, S. (1996). Foreign subsidiary compensation strategy: An agency theory perspective. Academy of Management Journal, 39(3): 678-703.

Schein, E. (1996). The three cultures of management: Implications for organizational learning. Sloan Management Review, 38: 9-20.

Schoemaker, P. J. H. (1982). Focused issue on the state of the art in theory and method in strategy research. Management Science, 36(10): 1178-1192.

Scullion, H., \& Collings, D. (2006). Global Staffing. London: Routledge Publishing.

Shenkar, O. (2001). Cultural distance revisited: Towards a more rigorous conceptualization and measurement of cultural differences. Journal of International Business Studies, 32(3): 519-536.

Simon, H. (1962). The architecture of complexity. Proceedings of the American Philosophical Society, 106: 467-482.

Singh, J. J., Vitell, S. J., Al-Khatib, J., \& Clark, I. (2007). The role of moral intensity and personal moral philosophies in the ethical decision making of marketers: A crosscultural comparison of China and the United States. Journal of International Marketing, 15(2): 86-112.

Sousa, C. M. P., \& Bradley, F. (2006). Cultural distance and psychic distance: Two peas in a pod? Journal of International Marketing, 14(1): 49-70.

Sterman, J. (1989). Modeling managerial behavior: Misperceptions of feedback in dynamic decision-making experiment. Management Science, 35(3): 331-342.

Sternberg, R. J. (1985). Beyond IQ: A triarchic theory of human intelligence. New York: Cambridge University Press.

Sternberg, R. J. (1996). Successful intelligence: How practical and creative intelligence determine success in life. New York: Simon \& Schuster.

Sternberg, R. J., \& Smith, C. (1985). Social intelligence and decoding skills in nonverbal communication. Social Cognition, 3(2): 168-192.

Sternberg, R. J. (1997). The triarchic theory of intelligence. In D. P. Flannagan, J. L. Genshaft, \& P. L. Harrison (Eds.), Contemporary intellectual assessment: Theories, tests, and issues (pp. 92-104). New York: Guilford Press.

Taylor, C. R., \& Okazaki, S. (2006). Who standardizes advertising more frequently, and why do they do so? A comparison of U.S. and Japanese subsidiaries' advertising practices in the European Union. Journal of International Marketing, 14(1): 98-120.

Tihanyi, L, Griffith, D. A., \& Russell, C. J. (2005). The effect of cultural distance on entry mode choice, international diversification, and MNE performance: A meta-analysis. Journal of International Business Studies, 36(3): 270-283.

Townsend, A., DeMarie, S., \& Hendrickson, A. (1998). Virtual teams: Technology and the workplace of the future. Academy of Management Executive, 12(3): 17-29.

Trompenaars, F. (1997). Riding the waves of culture. London: Nicholas Breakley.

Tversky, A., \& Kahneman, R. (1986). Rational choice and the framing of decisions. Journal of Business, 59(4): 91-104.

Vincent, A., \& Ross, D. (2001). Personalize training: Determine learning styles, personality types, and multiple intelligences online. The Learning Organization, 8(1): 3643.

Wagner, R., \& Sternberg, R. (1986). Tacit knowledge and intelligence in the everyday world. In R. Sternberg \& R. Wagner (Eds.), Practical intelligence: Nature and origins of competence in the everyday world (pp. 51-83). Cambridge: Cambridge University Press.

West, M. (2002). Sparkling fountains or stagnant ponds: An integrative model of creativity and innovation implementation in groups. Applied Psychology, 51(3): 355-387.

White, P. D. (1979). Attitudes of U.S. purchasing managers toward industrial products manufactured in selected western European nations. Journal of International Business Studies, 10(1): 81-90

Williamson, O. (1993). Calculativeness, trust and economic organization. Journal of Law and Economics, 36: 453-486.

Woodman, R., Sawyer, J., \& Griffin, R. (1993). Toward a theory of organizational creativity. Academy of Management Review, 18(2): 293-321.

Wright, P. M., \& McMahan, G. C. (1992). Theoretical perspectives for strategic human resource management. Journal of Management, 18(2): 295-320. 